\title{
The measurements and simulations of the ship thermal signature
}

by M. Zieliński

"Polish Naval Academy, Gdynia, Poland

\section{Abstrakt}

The paper presents the ship thermal signature comparison between the measurement and simulations made in the NTCS program. In September 2001 I was participated in the SIMVEX trial in Halifax - Canada.

The SIMVEX trial had two objectives:

- the comparison of radiometric measurements from the various participating NATO countries in order to validate their methodology;

- the collection of high quality UNCLASSIFIED radiometric data on a test ship for subsequent collaborative validation of the ShipIR programme.

During the trial, comparisons were performed on the ship CFAV Quest. The ship was made available by Canada for this trial.

\section{Introduction}

In September 2001 I was participated in the SIMVEX trial in Halifax - Canada.

The SIMVEX trial had two objectives:

- the comparison of radiometric measurements from the various participating NATO countries in order to validate their methodology;

- the collection of high quality UNCLASSIFIED radiometric data on a test ship for subsequent collaborative validation of the ShipIR.

During the trial, comparisons were performed on the ship CFAV Quest. The ship was made available by Canada for this trial.

For the ship equivalent blackbody temperature of a part of the port hull was compared. Figure 1. shows an image of the ship.

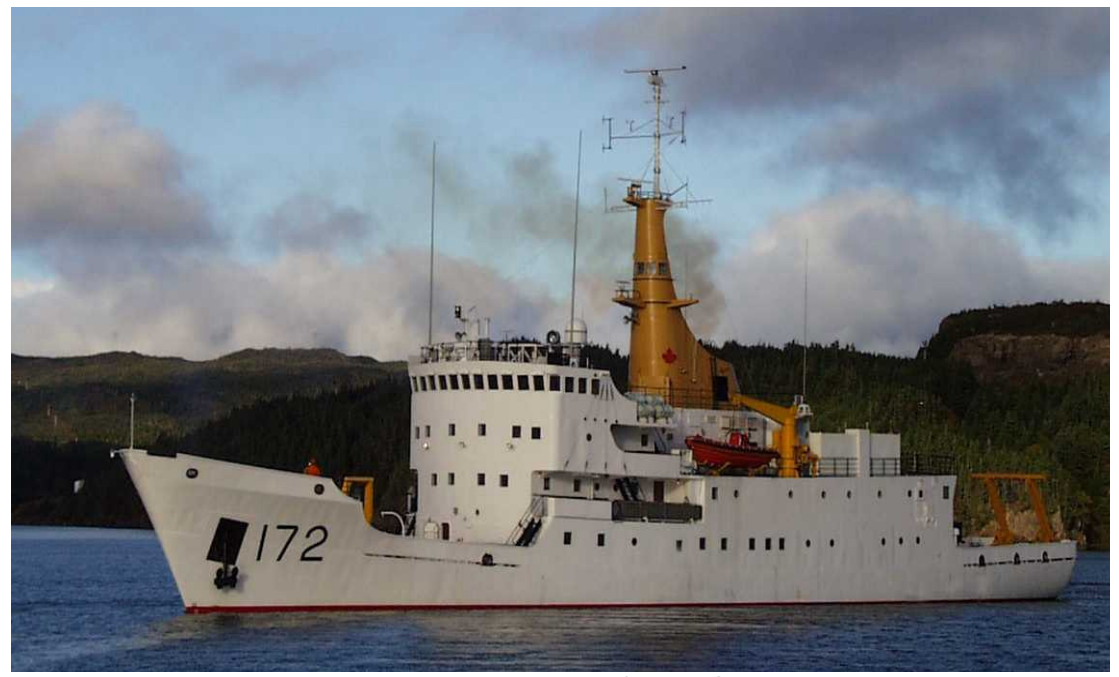

Fig. 1. Image of the CFAV Quest.

\section{Measurements}

The measurements were performed at the FMF Cape Scott test facility (NESTRA) at Osborne Head, Halifax - Canada. I was on this trial in September 15 to 21.

Figure 2. shows all the different measurement teams in position.

Poland participated in runs 14 to 40 without $23,25,28,30,33,36$ and 37 (there were plum runs). I measured the temperature on selecting area on the ship (excluding the window). This area (red box) is shown in the figure 3 . 


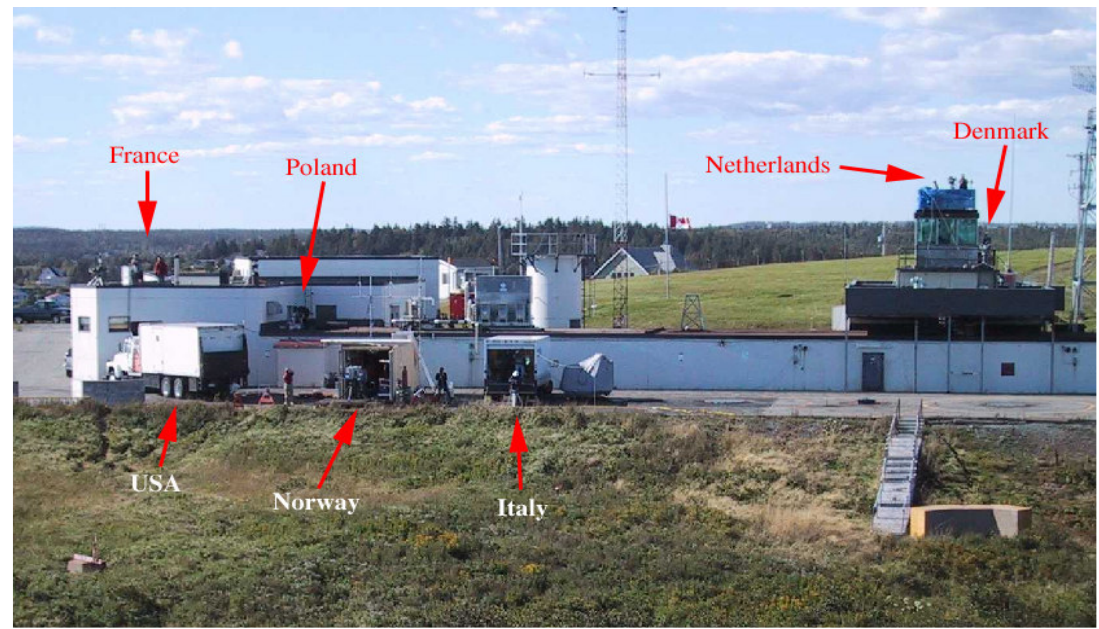

Fig. 2. The NESTRA with position all teams.

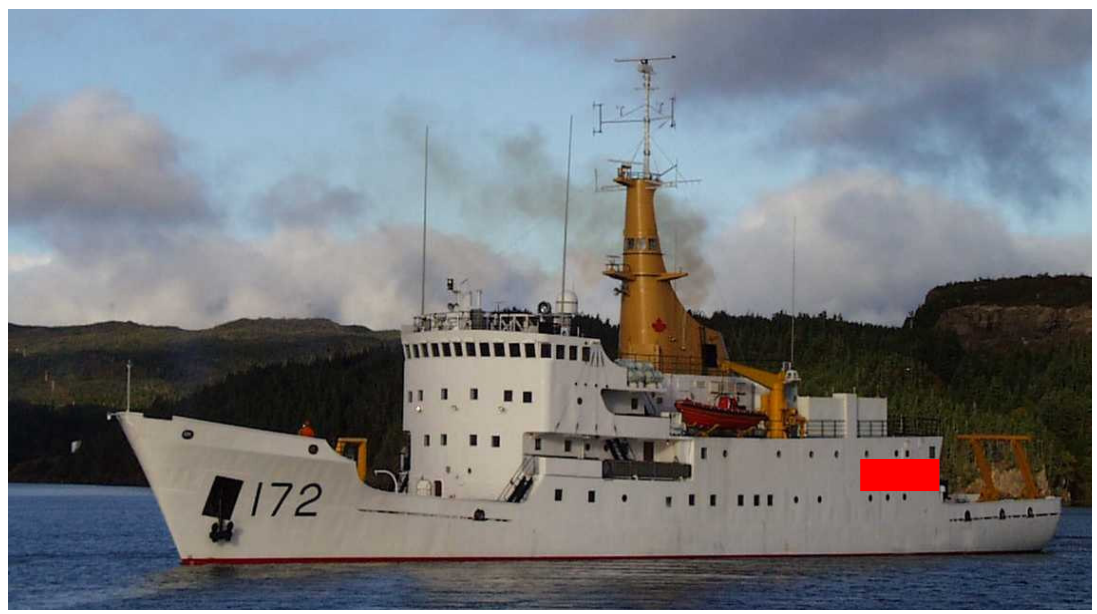

Fig. 3. Position of the measured area on the ship.

\section{Instrumentation}

I used the AGEMA 900LW camera with $5^{0}$ lens. This camera is with Stirling cooler and work in $8-12 \mu \mathrm{m}$ band. The image sequences were recorded on notebook. Average distance from my post to the ship Quest was $1007.5 \mathrm{~m}$ and altitude $27.9 \mathrm{~m}$. A photo of the post is shown in the figure 4 .

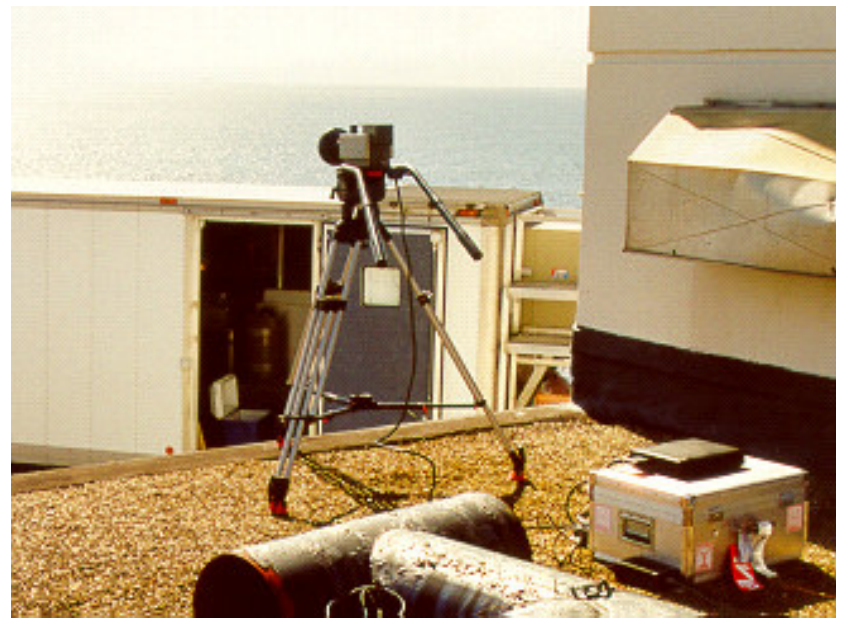

Fig. 4. The polish measurement post.

All information about whether conditions was measured by Norwegian team and they informed about this all other teams. 


\section{Run geometry}

During the trial, mainly four different types of runs were performed (it is shown in the figure 5.).

The run types were:

- type A - the starboard side of the ship was measured in shaded conditions, these runs were performed in day;

- $\quad$ type B - the port side of the ship was measured in sunlit conditions, these runs were performed in day;

- $\quad$ type $\mathrm{C}$ - the port side of the ship was measured in sunlit conditions, these runs were performed an evening;

- $\quad$ type $D$ - both the port and starboard were measured, these runs were performed in night.

The ship sailed with a constant speed and heading for all four types of runs. The reason for using a constant speed and heading was to allow the ship to reach thermal equilibrium before the measurement was taken.

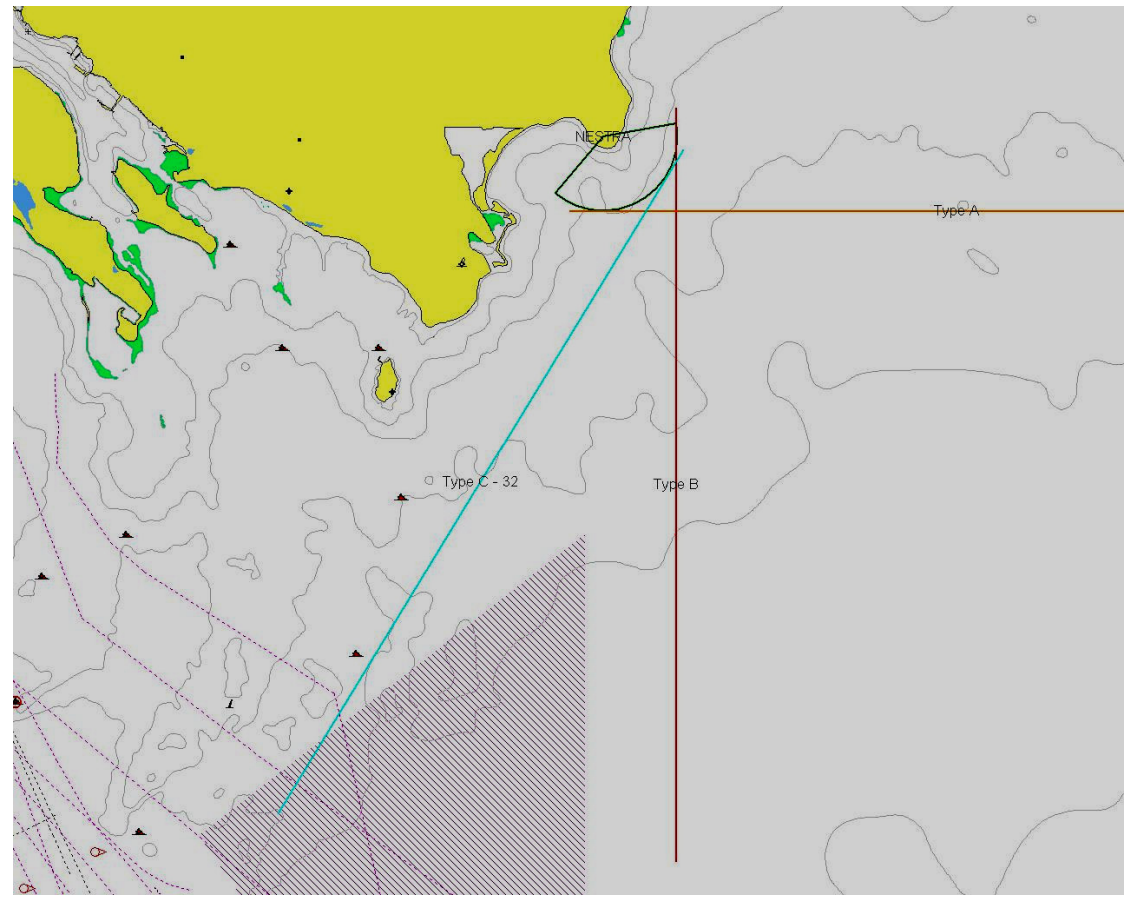

Fig. 5. Map of measurement area.

\section{Measurements and simulations}

The measurements of temperature on a chosen part of the CFAV Quest ship (shown in the figure 3.) were done by the set described in the $3^{\text {rd }}$ chapter. The ShipIR/NTCS (Naval Threat Countermeasure Simulator) was originally developed by Davis Engineering Ltd. with funding of the Canadian Department of National Defence, through the Defence Research and Development Canada Valcartier (DRDC).

The model of CFAV Quest and a complete ShipIR/NTCS input target file was developed for the trial by $N R L$ and Davis Engineering LTD respectively.

Simulations were performed in the LW infrared bands. Complete meteorological data, the observer height and distance, field of view of the camera, ship speed, heading and bearing were input into ShipIR for calculations. I used the Norwegian meteorological data for calculations. The standard MODTRAN mid latitude summer atmospheric profile scaled with the Norwegian meteorological data was used throughout the simulations. The Navy Aerosol Model (NAM) was used for the aerosols, Cox and Munk roughness parameters were used for the sea model and sea glint was set to normal. The computed ship temperatures were mainly read directly from the screen image in ShiplR and could also be exported.

\section{Day runs}

The results of measurements and simulations for the day runs are shown in table 1. and in graph 1. 
Table 1.

\begin{tabular}{|c|c|c|c|c|}
\hline \multirow[t]{2}{*}{ Run } & \multirow[t]{2}{*}{ Type } & \multirow{2}{*}{$\begin{array}{l}\text { Time } \\
\text { GMT }\end{array}$} & \multicolumn{2}{|l|}{$\mathrm{T}_{\text {ave }}$} \\
\hline & & & Agema & NTCS \\
\hline $14 \mathrm{C}$ & $C$ & $21: 00$ & 21.4 & 20.8 \\
\hline $17 \mathrm{~B}$ & $B$ & $17: 00$ & 16.4 & 21.9 \\
\hline $18 \mathrm{~A}$ & A & $17: 30$ & 15.6 & 19.6 \\
\hline $19 \mathrm{C}$ & $\mathrm{C}$ & $21: 00$ & 20.8 & 19.1 \\
\hline $22 \mathrm{~B}$ & $B$ & $17: 00$ & 17.4 & 29.6 \\
\hline $24 \mathrm{C}$ & C & $21: 00$ & 18.9 & 20.6 \\
\hline $29 \mathrm{~B}$ & B & $17: 10$ & 18.2 & 28 \\
\hline $31 \mathrm{~A}$ & A & $18: 35$ & 17.6 & 22.1 \\
\hline $32 \mathrm{C}$ & C & $20: 50$ & 20.7 & 19 \\
\hline $38 \mathrm{C}$ & C & $21: 00$ & 17.8 & 19.5 \\
\hline
\end{tabular}

Graph 1.

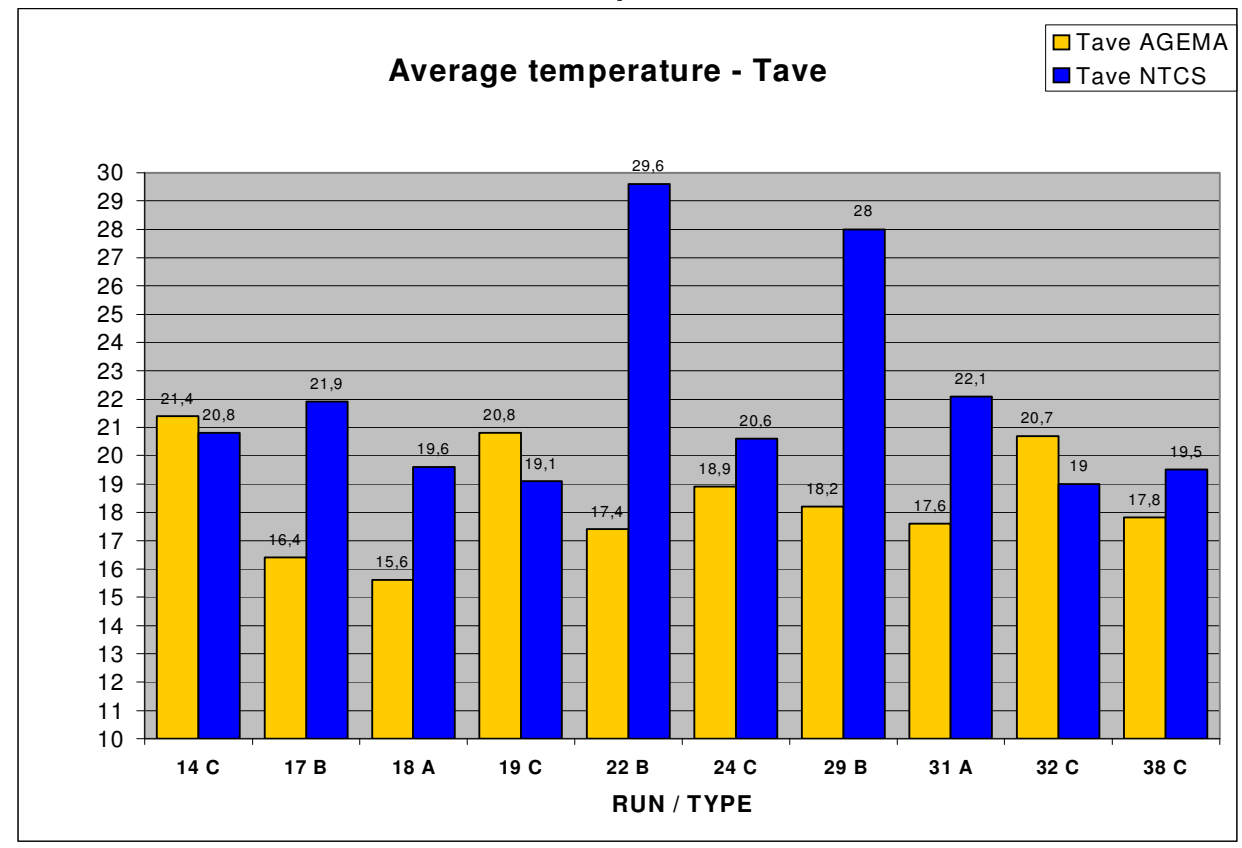

A big influence of sun was clearly seen in the results of measurement done during the day runs. Particularly in B and $C$ runs were the portside of a ship is measured while the sun shining on it. The total of temperature is very sensitive with the setting of a ship and the sun. It is mainly visible in B runs, where we can see an obvious difference between total measured by means of thermovision camera and a temperature of thermocouple installed on the surface of a ship.

In the case of measurements of $C$ runs (where the starboard was measured in the shadow) the differences are not big and clearly smaller than the average and standard deviation for the difference of temperatures measured with the thermovision camera and thermocouple.

The calculated temperatures in NTCS are typically higher than measured temperatures in day runs. There is not much correlation with the air temperature and sun glint.

For the B runs clearly in simulation of the temperature totals, in the same area as for the measurements, they are bigger even than $27 \%$. It is probably a result of the fact that in the simulation, much bigger part of solar radiation is considered as an effect of reflection from the ship's surface, and partially clouded sky is not taken into consideration (in the simulation only clear or totally clouded sky is accepted).

In the case of $C$ runs it is less visible, probably for the reason that in these runs there is minor force of solar radiation admitted to the simulation and it is in the shadow.

\section{Night runs}

The results of the measurements and simulations for the night runs are presented in table 2. and in graphs 2., 3. and 4. 
Table 2.

\begin{tabular}{|c|c|c|c|c|c|c|c|}
\hline \multirow[t]{3}{*}{ Run } & \multirow[t]{3}{*}{ 2.1. Type } & \multirow{2}{*}{\multicolumn{2}{|c|}{ 2.2. Time/GMT }} & \multicolumn{4}{|l|}{$\overline{\mathrm{T}_{\text {ave }}}$} \\
\hline & & & & \multicolumn{2}{|c|}{ Agema } & \multicolumn{2}{|c|}{ NTCS } \\
\hline & & Port & Starboard & Port & Starboard & Port & Starboard \\
\hline 15 & $\mathrm{D}$ & $23: 30$ & $23: 40$ & 14.5 & 15 & 17.4 & 16.3 \\
\hline 16 & $\bar{D}$ & $00: 30$ & $00: 40$ & 14.5 & 13.9 & 11.2 & 15.7 \\
\hline 20 & $\mathrm{D}$ & $23: 30$ & $23: 40$ & 15.6 & 16 & 10.7 & 14.7 \\
\hline 21 & $\mathrm{D}$ & $00: 15$ & $00: 25$ & 15.8 & 15.6 & 16.1 & 16.7 \\
\hline 26 & $D$ & $23: 25$ & $23: 35$ & 16.5 & 16.5 & 16.9 & 17.5 \\
\hline 27 & $\bar{D}$ & $00: 18$ & $00: 26$ & 16.4 & 16.4 & 12.7 & 13.6 \\
\hline 34 & $\mathrm{D}$ & $23: 30$ & 23:39 & 15.3 & 15.5 & 18.4 & 16.7 \\
\hline 35 & $\mathrm{D}$ & $00: 20$ & $00: 30$ & 15 & 14.8 & 9.51 & 14.2 \\
\hline 39 & $\bar{D}$ & $23: 30$ & $23: 38$ & 16 & 16.2 & 12.2 & 14.1 \\
\hline 40 & $\mathrm{D}$ & $00: 25$ & $00: 33$ & 15.7 & 15.8 & 12.7 & 11.5 \\
\hline
\end{tabular}

Graph 2.

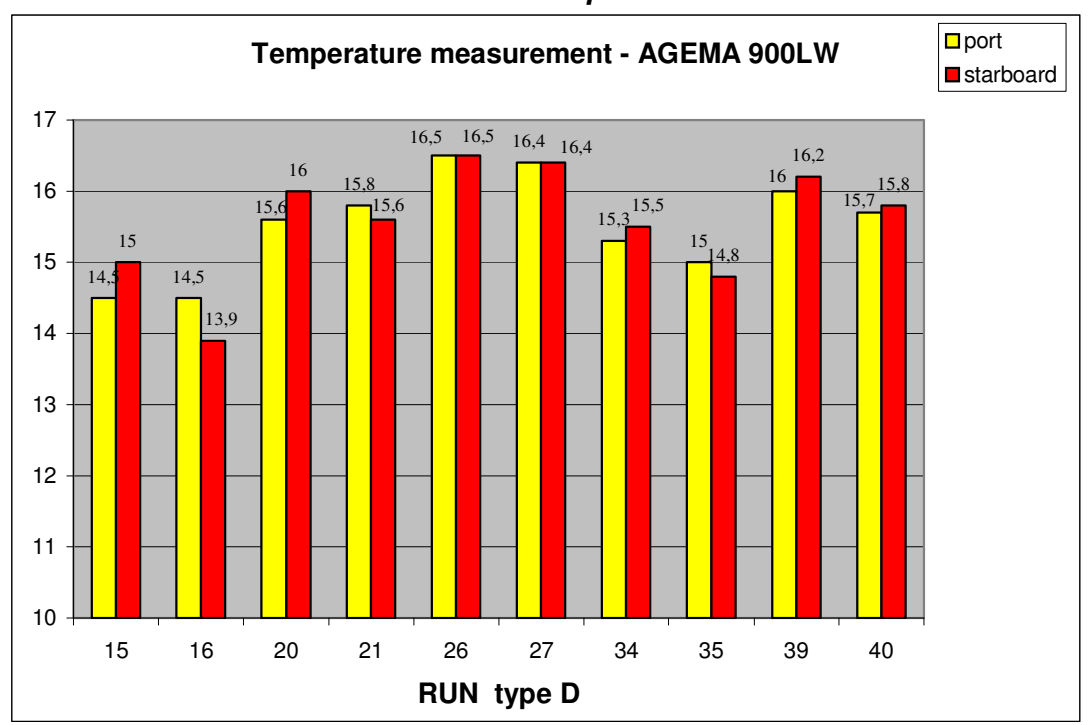

Graph 3.

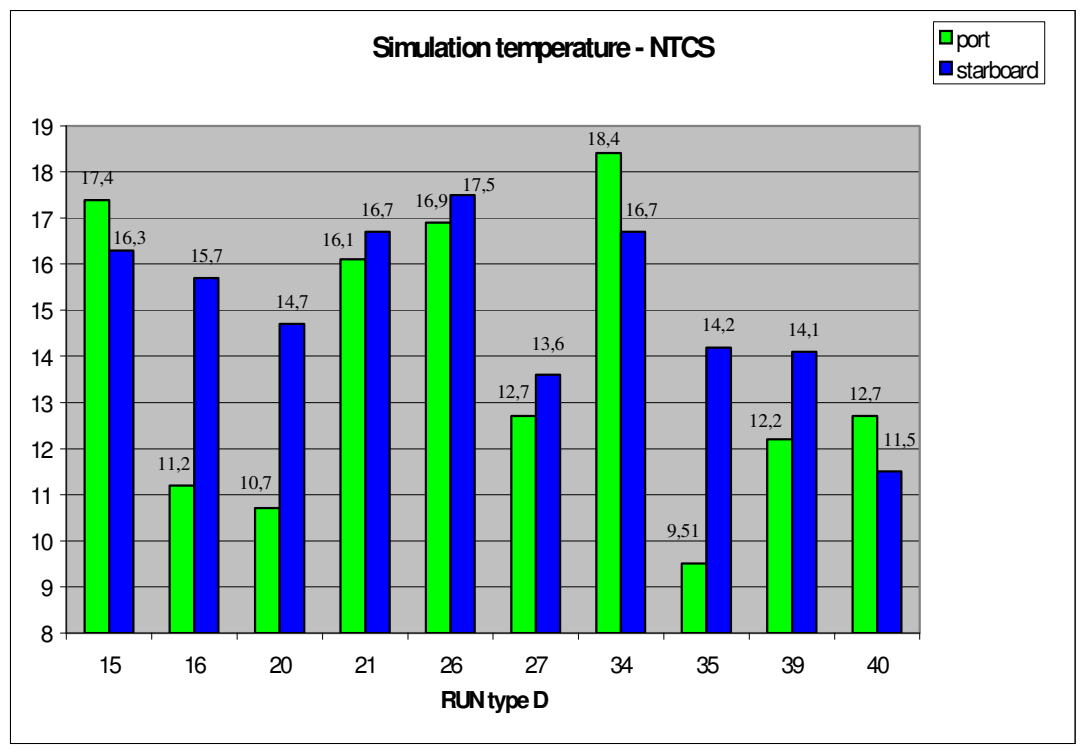


Graph 4.

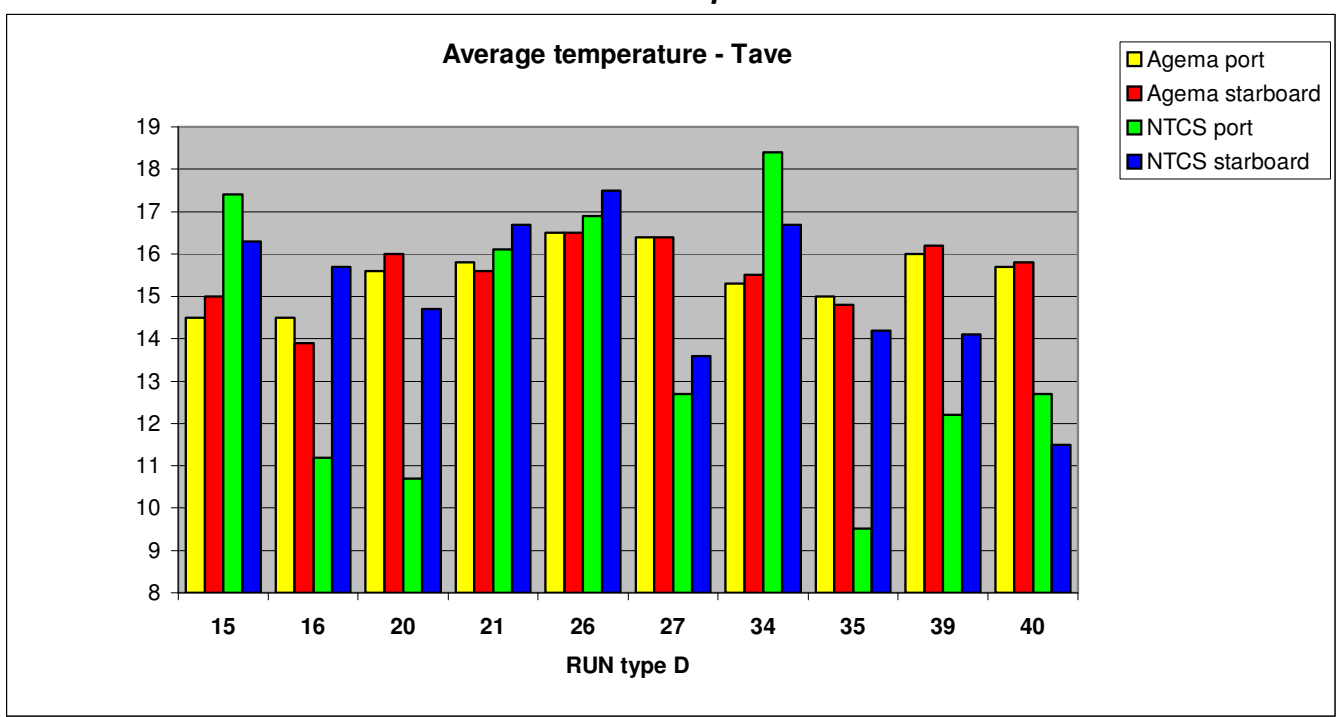

The measured port's totals are mainly smaller than starboard's. In the night measurements the result was mainly influenced by the wind (its direction and speed) and the differences in the construction of the boards. These differences are visible in the figure 6.

On the starboard, there are two areas of higher temperature (they may be exits of air-conditioning or elements of galley's or engine rooms' ventilators).

In the case of windy weather, the convective heat-transfer coefficient is larger. In the case of quiet weather and clear sky, due to radiation cooling the convective heat-transfer coefficient is small and the temperature of the surface is lower than ambient temperature.

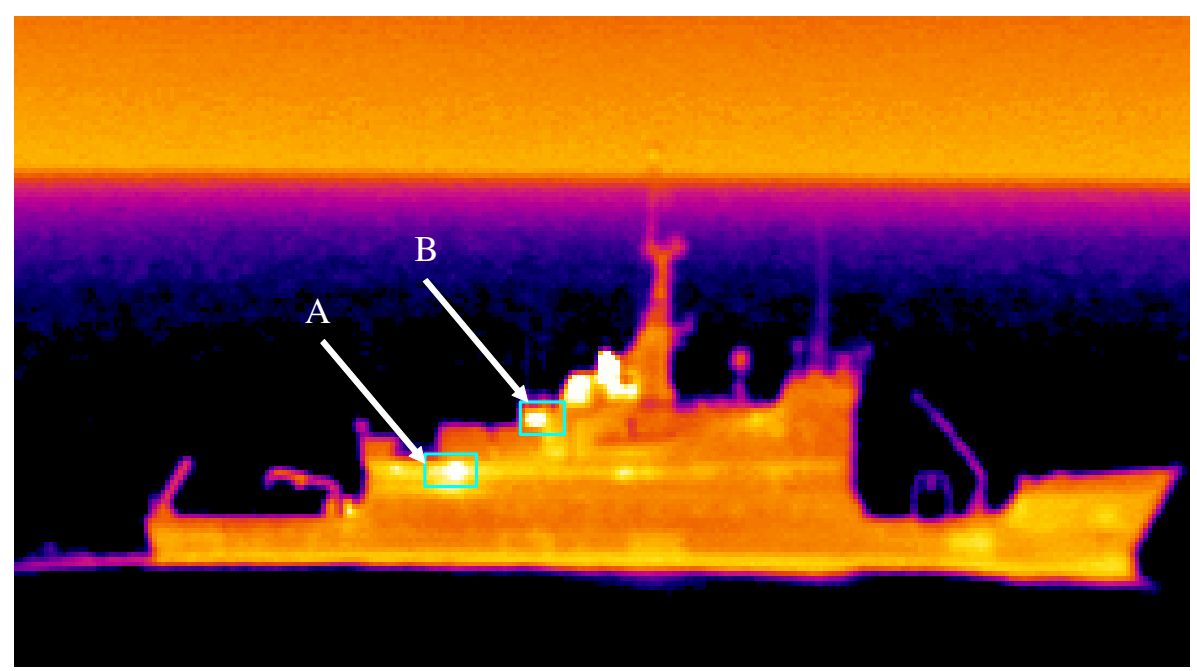

Fig. 6.

From regard on direction of wind, which in the 15,20,26,27,39 and 40 runs' case was more or less like the ship's speed, and in concord with its course, it's seen that the port has lower temperature than the starboard.

In the night's calculations, the average total of the difference between the total measured with the help of the thermovision camera and thermocouple is close to 0 (it is " -0.025 "), which is the base to accept the correctness of carrying out the measurements. Only $30 \%$ of the calculations had bigger difference than an average deviation, and less than $20 \%$ of measurements exceeded the sum of standard deviation (including a half, which did it insignificantly).

The calculated temperatures in NTCS are typically lower than the measured temperatures.

In the case of simulations it is also seen that mainly the starboard has a higher temperature than the port's one. It is probably an effect of accepting meteorological data in the simulation, which were the same as for the portside's. However, the difference in time between the measurement of the portside and starboard fluctuated between 8-12 minutes, and thus the meteorological data were changing. Accepting the meteorological data from a certain time in the simulation corrects these totals between $10-15 \%$. 


\section{Conclusions}

In the case of carrying the measurements with the thermovision camera AGEMA 900 LW, the C type measurements were burdened with the smaller measuring mistake. It is shown in 5.1. chapter.

In the case of day runs simulations it is seen that the temperature in given area is higher than the temperature measured with the thermovision camera and thermocouple. It probably results from not very proper correlation with the temperature of the air and solar radiation in the ShipIR/NTCS's model of atmosphere.

The night runs were carried out the most, what enables performing more complete comparison between the measured and simulated totals. The general tendency, in the case of simulation results, is that they are mainly lower than in the case of the measurements. It may be also notified that the difference between the measured temperature and the one being the result of simulations lower than in the case of day runs. It probably results from not taking into consideration the solar radiation in the simulation, which probably makes some procedures easier and accelerates ShipIR/NTCS's work. However, too much attention was probably attached to the wind parameters (mainly speed and direction) in the case of day runs, for the windy weather and wind directions in concord with the ship's course the differences between the measured total and the one of simulation are rather significant (bigger than the standard deviation for the port's temperature).

The discussion on these runs was led in 5.2. chapter.

The mistakes and differences in the results measured and obtained from simulations may be the effect of the fact that the model of the ship wasn't complete and the meteorological data weren't accurate enough to present complete balanced situation (equilibrium) on the ship ( $B$ and $C$ measurements - the influence of sun).

\section{REFERENCES}

[1] Thermovision 900 Series. Users' Manual. Vol.1.

[2] Thermovision 900 Series. Users' Manual. Vol.2.

[3] ShipIR/NTCS Simulation Software. Users' Manual 
http://dx.doi.org/10.21611/qirt.2008.09_06_06 